\title{
The demographic impacts of the Irish famine: towards a greater geographical understanding
}

\author{
A Stewart Fotheringham ${ }^{1}$, Mary H Kelly ${ }^{2}$ and Martin Charlton ${ }^{3}$
}

The Irish famine of the 1840s had a dramatic effect both on the population within Ireland and the populations of countries such as the US, the UK and Australia, which received the bulk of the Irish diaspora resulting from the famine (Kenny 2003). As such, the effects of the famine have been examined extensively across a range of disciplines. It is therefore a challenge to provide any new perspective on this well-researched area. However, this paper provides novel insights into the spatial effects of the famine on population in two ways. Firstly, we present the most spatially detailed data recorded to date on population change in the period 1841-51 covering the famine. We are able to do this by, for the first time, linking census data from 1851 (which also records 1841 population) to the boundaries of 3436 Electoral Divisions (EDs) to provide a very detailed description of the uneven nature of population change during the famine decade. Secondly, by collecting data at the same spatial scale for over 100 other variables, we are able to analyse the relationship between population change during this decade and various demographic, locational and land use characteristics of EDs. We do this through not only traditional regression but also by geographically weighted regression (GWR), which allows us to investigate possible spatial variations in the determinants of population change during the famine period. The results of this analysis raise a series of intriguing new questions relating to the effect of the Irish famine on population change and point the way to further detailed historical and geographical research on this important topic. The research also demonstrates the use of GIS and spatial analytical techniques in historical geography as a means of uncovering new questions that can be answered by further qualitative research.

Key words Irish famine; historical GIS; population dynamics; geographically weighted regression

${ }^{1}$ Centre for Geoinformatics Department of Geography and Sustainable Development, School of Geography and Geosciences, Irvine Building, University of St Andrews, St Andrews, Fife KY16 9TF, Scotland, UK

${ }^{2}$ Department of Geography, National University of Ireland Maynooth, Maynooth, Co. Kildare, Ireland

${ }^{3}$ National Centre for Geocomputation, National University of Ireland Maynooth, Maynooth, Co. Kildare, Ireland

Email: mary.h.kelly@nuim.ie

Revised manuscript received 4 February 2012

\section{Introduction}

The Irish famine of the 1840 s is an important and highly emotive event in Irish population history. Figure 1 displays the total Irish population (the Republic of Ireland and Northern Ireland) from 1821 to 2006 and reveals the devastating impact of the famine, not only by the dramatic decline in population between 1841 and 1851 (the decade in which the famine occurred), but also by the long-lasting impact this had, such that the current population is still only three-quarters of what it was in 1841.

Because of its importance, a great deal of research has been undertaken on the impact of the famine on Irish demography. Such work has revealed that the impacts of the famine were neither shared equally among the populace (O'Grada 2006) nor distributed evenly across the landscape (Kennedy et al. 1999; O’Grada 1999; Póirtéir 1995), and it is now recognised that the reasons why the failure of the potato crop in the 1840 s had such cataclysmic impact on population numbers are varied and complex. Malthusian proponents suggest that Ireland was overpopulated on the eve of the famine and consequently interpret the famine as a disaster waiting to happen (Connell 1975; Freeman 1957; Grigg 1980). Others argue that the famine was the result of a system of landownership that forced the majority of the population to live on marginal lands where the potato was the sole form of sustenance (Kinealy 1997; O'Grada 1993; Smyth 1983). Failures of that crop between 1845 and 1849 consequently resulted in an inability of large numbers of people to feed themselves. Others argue that the demographic disaster that resulted from the potato blight could have been lessened had the government response to the disaster been instituted more humanely, more quickly and more effectively (Gray 1999; Lloyd 2007). Finally more recent analysis argues that population losses caused by famine deaths and emigration were largely orchestrated by policies for social reform drawn up in Westminster (Nally 2011). 


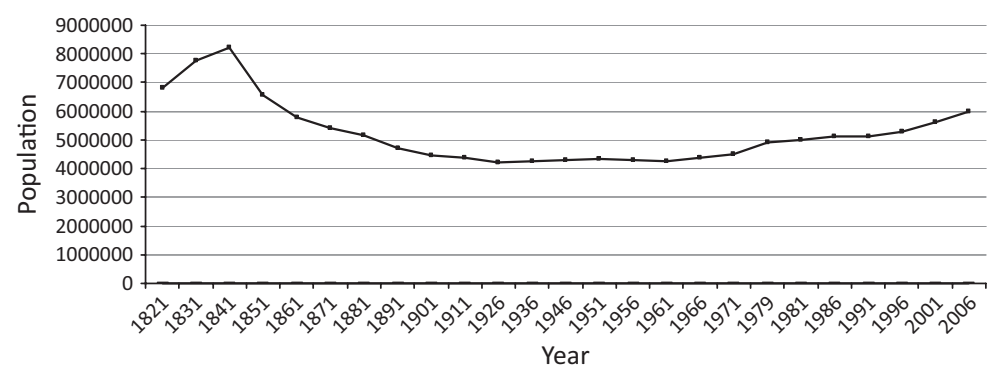

Figure 1 Population change in Ireland 1821-2006

One reason why debate over the causes of the famine continues stems from the fact that population decline is a multifaceted phenomenon having several determining factors. A second reason relates to the fact that the impacts of the famine were felt differently in different areas. This has been borne out by those that have mapped population change at various scales (Kennedy et al. 1999; Smyth 2007) and by the wealth of local studies that demonstrate the significance of local contexts and local responses (Cowman 1995; Hickey 1995; Kinealy and Parkhill 1997; Murphy 1996; Yager 1996). Consequently, as the processes that impacted upon population change appear to have varied significantly from place to place, consensus on the extent to which particular factors were significant has been difficult to achieve. Moreover, analyses carried out at a range of spatial scales suggest that the likelihood of survival might have been determined not only by demographic and land use factors but also by locational issues such as topography and proximity to workhouses (Guinnane and O'Grada 2000), ports (McDonagh 1956), urban areas and the coast (Jones-Hughes 1965; O'Grada 2006).

Thus, while the literature presents us with many of the factors that may have aggravated or ameliorated the impacts of the famine, little rigorous testing of ideas has taken place and the localised nature of much Irish famine research means that it has not been possible to examine the significance of contributing factors at a national scale. Where quantitative spatial analysis has been undertaken, it has been limited to spatial scales that are too coarse to pick up local detail (Ell and Gregory 2005; Gregory and Ell 2005). Consequently, there is a need to examine the demographic impacts of the famine at a national scale using more detailed spatial data than has previously been reported.

This paper addresses this need by mapping population change as well as aspects of the human and physical landscape that may have abated or exacerbated population decline at a much finer spatial scale, that of the 3436 Electoral Divisions (EDs), than has previously been achieved and then analysing the determinants of population change at this fine spatial scale. We recognise that it is not possible to include all of the variables that could have impacted on population change in local areas. The contribution of benevolent landlords and charitable organisations, for example, may have alleviated suffering and consequently population loss in particular areas, while the implementation of assisted migration schemes would have exacerbated population loss (Duffy 2004). Due to the difficulty in collecting island-wide data on these variables for each ED, their effects will only be seen in the residuals of the models for certain areas. However, we are fortunate in being able to collect data on a large array of potentially relevant attributes that have been identified in the literature as factors that impacted on population numbers. ${ }^{1}$ Using standard regression analysis for over $3000 \mathrm{EDs}$ on the entire island of Ireland, we quantify the extent to which the characteristics of these EDs affected population change nationally, thereby providing a broad overview of the processes that might have been operating to create the unevenness of population change. However, because standard regression can hide many interesting local contextual effects that we suspect help explain the complicated spatial variation in population change during the famine decade, this paper also uses geographically weighted regression (GWR) to examine possible spatial variations in the impact that variables had on population change. This analysis, therefore, bridges the gap between the broader national explanations that have been put forward in Irish famine historiography and the local contexts in which the famine was experienced, whilst also providing a perspective on how the processes that affected population change in Ireland at this particular time were context-dependent and hence varied locally.

The first part of this paper outlines the manner in which data for this analysis were collected, organised and mapped at the ED level. For the first time a highly detailed picture of population dynamics during the decade of the famine is presented and discussed. It is shown that although there are broad regional trends in the impacts of the famine with the south and the west generally suffering more than the north and the east, there are very strong local variations within each region of the country. Indeed the whole 
picture of the effects of the famine in terms of population decline is a very complex mosaic. The second part of the paper discusses possible reasons for the spatial variation in population change as a result of the famine and identifies general determinants of population change at the ED level through a national-level analysis. The third part focuses on local or contextual variations in the determinants of population change during the famine decade from a GWR analysis perspective. Here we demonstrate how some determinants of population change were important in some parts of the country but not in others. In doing so we raise a new set of questions for further research and outline a likely explanation for why there is little or no national-level consensus on the effects of the famine. The final part of the paper outlines how this kind of research can deepen our understanding of the processes that underpin population change and highlights the benefits of combining quantitative and qualitative approaches within historical GIS to better understand geographical processes.

\section{Mapping population change in Ireland 1841-51}

There have been several previous attempts to describe the spatially varying impacts of the famine through mapping population change 1841-51. However, the majority of these have been at crude spatial scales. Kennedy et al. (1999) map population change at three scales: the 32 counties; the 163 Poor Law Unions; and the 334 baronies. Ell and Gregory (2005) also map population change at both the Poor Law Union and barony levels, the latter containing a statistical analysis of these data (Ell and Gregory 2005; Gregory and Ell 2005). The most detailed mapping to date is that of Smyth (2007), who maps population change 1841-51 for the 2426 civil parishes in Ireland. In this paper we are able to map population change at an even finer scale - that of the 3436 EDs.

Using data gathered by the 1841 and 1851 census enumerators, population change is mapped here at ED level for the entire country for the first time. EDs were first introduced into Ireland in 1838 as a unit through which Irish poor relief was to be administered and census data collected (O'Brien 1982). While the 1841 census was collected at the traditional parish and barony level, the 1851 Census enumerators recalculated the 1841 data at $\mathrm{ED}$ level to facilitate comparison between pre- and post-famine Ireland at one common spatial scale. In doing so, the census enumerators have left us with a valuable lens through which spatial comparisons can be examined, but that has not yet been used in Irish famine research. The data presented in the census returns include total population per ED in 1841 and 1851, male-female ratio 1841 and 1851, the number of inhabited houses, uninhabited houses and houses under construction as well as the poor law valuation and area of each ED. From these variables, additional data can be calculated such as population density and people per building, thereby providing us with measures of overpopulation. Inputting these data into an historical GIS based on a digitised set of 1851 ED boundaries allows us to map them, giving a detailed perspective on spatial variation in population change as well as on some of the variables that might have impacted on that change.

Figure 2 describes the focus of this paper - percentage population change between 1841 and 1851 by ED. This detailed mapping of population change during the famine decade clearly shows the extent to which some local communities were devastated by the effects of the famine, losing over 50 per cent of their population, while other EDs, mainly urban communities, gained population. ${ }^{2}$ The broad trend is one where the effects of the famine were generally greater in the west and south, with the east and the north being less severely affected. However, this broad trend disguises many local variations, the description of which is aided by the key map in Figure 3. For example, some EDs in the north and east, such as those in Co. Tyrone and Co. Meath, experienced just as severe population decline

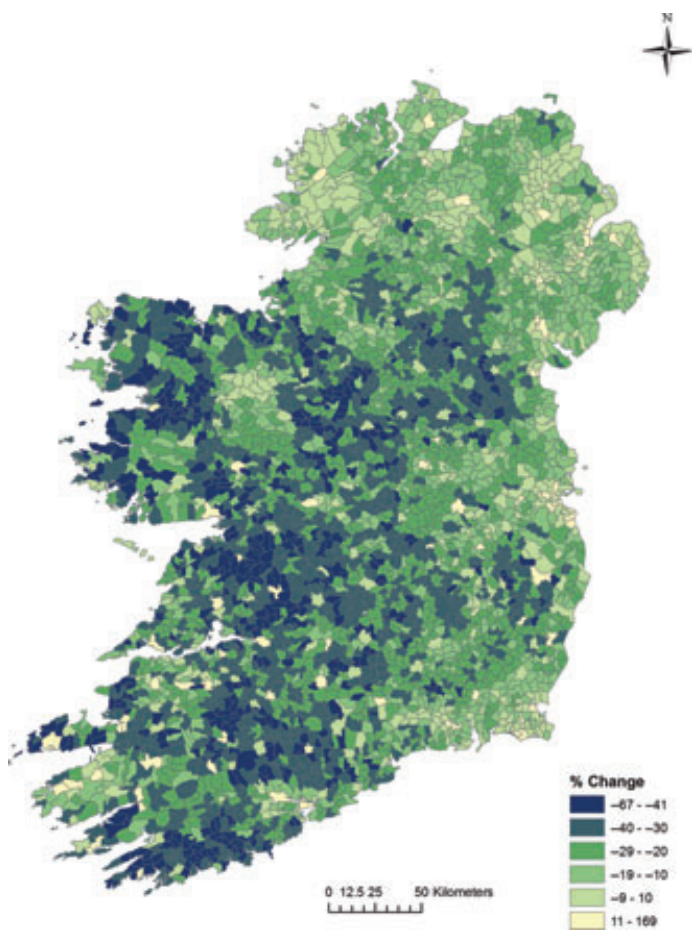

Figure 2 Percent population change 1841-1851 


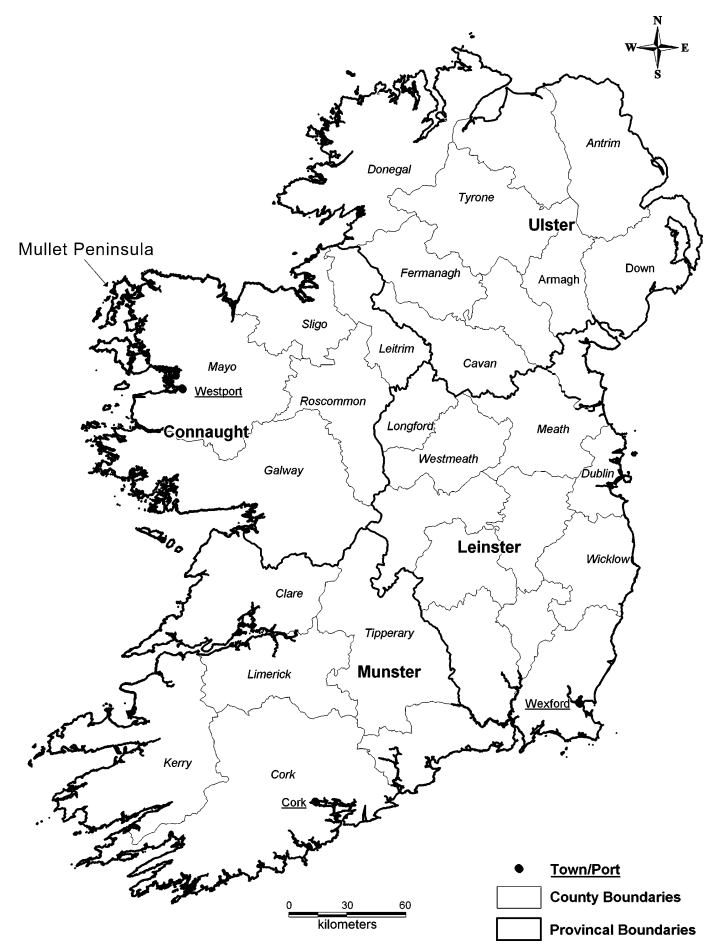

Figure 3 Key map

as did EDs in the west. Equally, some EDs in the west, such as some of those in Co. Clare and Co. Kerry, experienced very little population decline. In some cases the famine had very different effects on population change even in neighbouring EDs, where dramatic variations can be seen. In Co. Mayo, for example, many of the EDs neighbouring the town of Westport experienced over 40 per cent population loss, while the town population increased by over 10 per cent. The town, being both a port and the location of a workhouse, probably absorbed some of the losses experienced by the surrounding EDs. Moreover, while EDs on and around the Mullet Peninsula experienced significant population loss, the EDs towards the north of the Peninsula were less severely affected. Similar local variations can also be seen in other parts of the country.

\section{Explaining spatial variation}

Providing explanations for the spatial variation in population change identified in Figure 2 is difficult for a number of reasons. Firstly, the variable of interest - population change - is a compound variable that results from multiple processes. Population loss can result from a high death rate, a low birth rate, net emigration and net out-migration ${ }^{3}$. During the Irish famine, all four of these processes impacted on population loss. Unfortunately, the data do not allow us to separate excess deaths from net emigration and net out-migration at ED level. Therefore, we have to recognise that we are trying to understand a complex process that needs explanations for both raised mortality rates and population movement (both emigration and out-migration).

Secondly, the factors that may have impacted on population change probably did so in complex ways and the processes by which they affected population change may have varied locally. Analysis of the detailed literature on the famine in local areas indicates that there was a range of mitigating circumstances that impacted on population change. These include rural over-population, proximity to the coast, poverty levels, the type of agriculture practised, overreliance on the potato and accessibility to towns and relief schemes. Some of these variables were the result of policies that had been implemented in the century and a half preceding the famine. Recent literature on the famine has explicitly demonstrated the manner in which colonial policy created the context in which Irish people were vulnerable to calamity (Nally 2011). Rural population pressure, poverty and over-dependence on the potato are variables that capture the effects of such policy and are factors that exacerbated population decline when blight struck in 1845. However, while these locational factors have been suggested as possible determinants of population change in some parts of the country, can we establish the extent to which these determinants operated at the national scale or varied locally? For example, while there is ample evidence that over-dependency on one crop, the potato, created the conditions ripe for a famine (Bourke 1993), was the relationship between potato dependency and population decline the same all over Ireland? To answer these questions we employ GWR (Fotheringham et al. 1996 2002) to calibrate local models relating population change to a set of possible determinants.

Thirdly, although Figure 2 depicts a general picture of severe population decline, it is interspersed with EDs exhibiting population growth. Most of these are urban EDs that did not have a strong agricultural base. In addition, the census of 1851 included institutionalised people, so that the populations of EDs containing workhouses, hospitals or prisons, largely urban EDs, will probably be considerably different from their 1841 values as the populations of many institutions, particularly workhouses, increased rapidly during the famine decade. ${ }^{4}$ Including such EDs would strongly bias any subsequent analysis aimed at understanding a largely rural set of processes. Consequently, this analysis concentrates on those primarily rural EDs (3098 out of 3436) that suffered population decline between 1841 and 1851. The focus of this paper, therefore, is on uncovering possible explanations 
for why some EDs suffered severe population loss during the famine whilst others suffered less so.

In order to address this issue, data on possible determinants of population decline were assembled for each ED. Fortunately, a wealth of data were collected around the time of the famine and published in the census of population and census of agriculture. In addition, topographic and locational variables that would not have changed perceptively since the 1840 s, such as mean elevation and proximity to coasts, were calculated from modern data sources. Thus, while the ability to collect new data is extremely limited, we are fortunate to be able to draw on the above sources to construct an extensive set of attributes relating to the famine period and to map these using a consistent set of ED polygons.

\section{Data sources}

As outlined above, the 1851 Population Census records demographic data for each ED for both 1841 and 1851. Agricultural censuses began in Ireland in 1847 with crop data being gathered at ED level. However, data collected in the early years are unreliable (O'Grada 1994) and, due to the fact that the ED network was still evolving at this time, not compatible with the territorial units used to collect the population census. It was not until 1851 that the agricultural data became more complete and the units for collection became compatible with the population census of the same year. Unfortunately, therefore we do not have a picture of crop agriculture at ED level in pre-famine Ireland. In the absence of a suitable source for 1841 through which to view the pre-famine landscape and map changes that took place between 1841 and 1851 at ED level, we have had to rely on the 1851 census as our lens on the agricultural practices of the time. Admittedly this is problematic, particularly with regard to the extent to which we can use the 1851 data as a surrogate for 1841 distributions. However, Bourke's (1965) work on the agricultural data supplied with the 1841 census and the later agricultural censuses indicates that there were approximately 14 million acres of cultivated land in Ireland in 1841, a figure similar to the total for 1851 . Thus total crop acres for 1851 might be taken as a fairly reliable surrogate for total crop acres in 1841, despite the fact that the amounts of individual crops may have changed. Potato acreage certainly changed. There were approximately 2 million acres of potatoes in Ireland 1844. By 1851 only 800000 acres were planted with potatoes (Bourke 1965/60). However, examination of Bourke's work on the potato survey of 1844-6 against the county totals recorded in 1851 shows that while there was a significant decrease in acres under potatoes between 1844 and 1851, in terms of the proportion of overall potato acres per county, the picture is relatively stable (Bourke
1959/60). Co. Cork, for example, contained 15 per cent of the country's potato acreage in 1844 and was the largest potato producer. Despite having lost over 70 per cent of its crop, Co. Cork was still the largest potato producer in 1851, containing 11 per cent of Irish potato acres. At the other end of the scale, Co. Dublin contained the country's smallest share of potato acres in both $1844(0.97 \%)$ and $1851(1.23 \%)$. Moreover, mapping the potato acres in 1851 (Figure 4b) shows higher concentrations of potato cultivation in the west of Ireland, as we would expect, where poverty and marginalisation were greatest. Thus, for our purposes, it is the stability in the relative distribution of crops that is important, rather than their actual amount. Another way to interpret the 1851 data is to regard them as the outcome of processes that occurred during the famine. We know from the holding size data published with the 1841 census that there was large-scale disappearance of small farms, a process that had been in operation, albeit more slowly, in the decades before the famine. Consequently, mapping the average holding size of EDs in 1851 could help us identify areas in which farm clearances had occurred to facilitate the creation of larger holdings or the expansion of grazing either before or during the famine. There were approximately 1 million more cattle in Ireland after the famine than before it and many contemporary observers bemoaned the extent to which cattle replaced people (Whelan 1995). Moreover, the Gregory clause, which stipulated that the destitute must relinquish their holdings in order to be eligible for relief, resulted in the large-scale disappearance of small holdings from the land. Thus, while acknowledging that using the 1851 agricultural census data as a lens on the geography of agricultural practice at the time of the famine is not ideal, we do so on the basis that although the absolute area under various crops changed from 1841 to 1851 , the relative spatial distributions of those crops did not, and that when interpreting the results we must bear in mind that variables mapped from the 1851 census may be the outcome of processes that occurred before, during or after the famine. With this caveat in mind, Figure 4 displays two attributes of agriculture that have been identified as potential determinants of the effects of the famine on population change. Figure 4a displays the population per acre of cropped land using 1841 population data and 1851 crop acreage, which, as reported by Bourke (1965), was the same in extent in 1851 as it was in 1841. The map in Figure 4a shows relatively high population pressure on the more marginal agricultural lands in the west of Ireland, with relatively little population pressure in the north and east.

Figure $4 \mathrm{~b}$ describes the percentage of each ED's crop land under potatoes in 1851 . This paints a pic- 

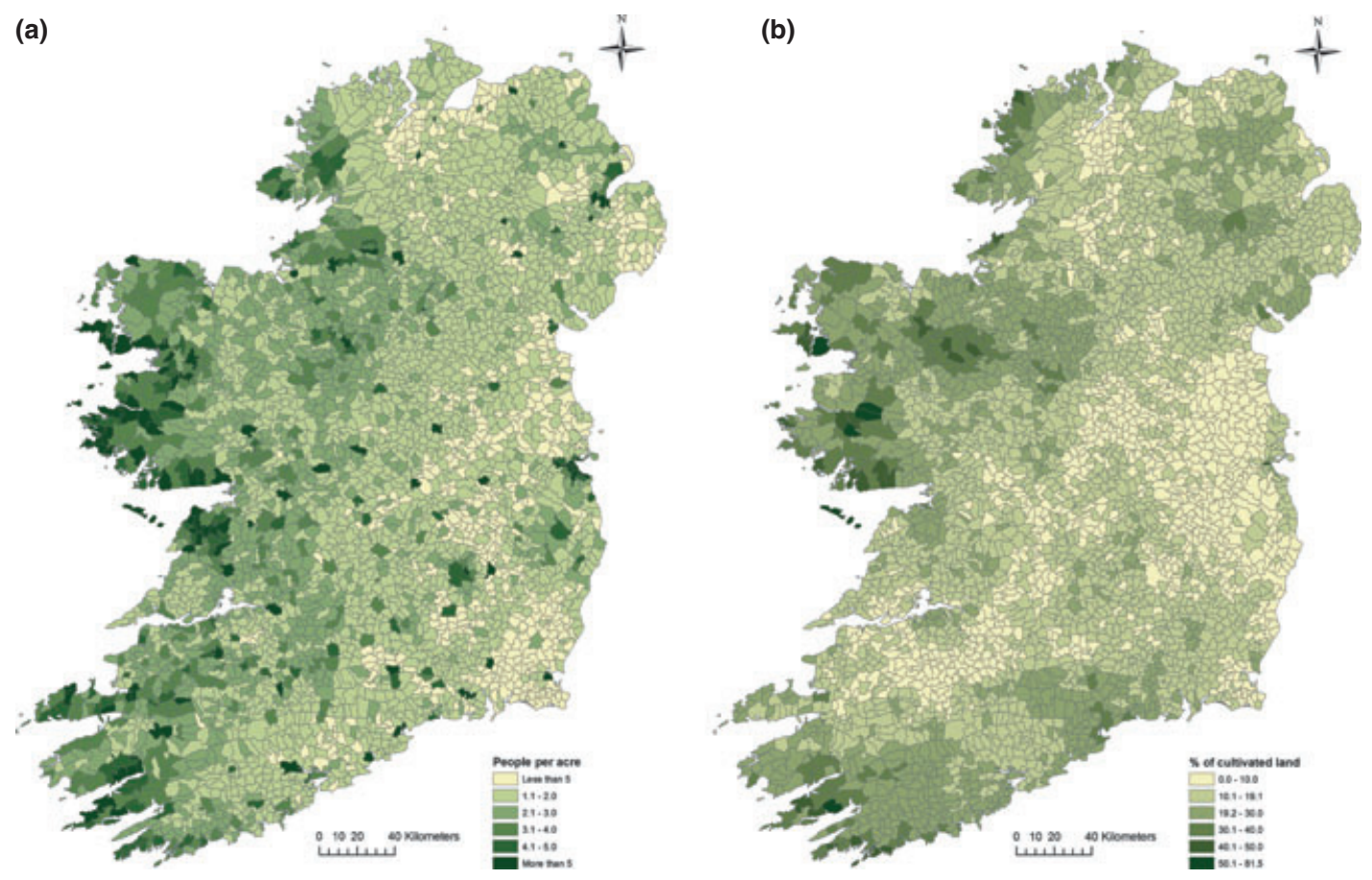

Figure 4 (a) Population density per acre of cropped land and (b) potato acre as percentage of crop acres

ture very much in accord with our view of pre-famine Ireland, with a heavy dependency on potatoes in parts of Donegal, most of the province of Connaught and the south-western tip of Kerry, where in some cases up to 80 per cent of the cropland was devoted to potato cultivation. In addition to these two sources of secondary data, locational variables such as the distance to the coast (a possible alternative source of food), proximity to workhouses (possible destinations as sources of relief), mean elevation (an indicator of more marginal land) and proximity to towns (again as possible destinations for rural migrants looking for food and employment) were calculated for each ED.

As a result, over 100 attributes representing the demographic, land use and locational characteristics of each of the 3098 EDs experiencing population decline of varying degrees between 1841 and 1851 were assembled. However, many of these variables were either not relevant to our understanding of the spatial variations in population change (such as the distribution of crops with very limited distribution across the country) or else were closely related to another, more pertinent, variable. Consequently, guided by the extensive literature on the Irish famine, we reduced our set of over 100 potential explanatory variables to 12 . These variables (listed in Table $\mathrm{I}^{5}$ ) and the rationale for selecting them are as follows:
1 Population density on cropped land: Ireland experienced rapid population growth in the first half of the nineteenth century and many contemporary observers as well as subsequent analysts have argued that overpopulation was one of the main factors that created a situation ripe for catastrophe (Connell 1975; Freeman 1957; Grigg 1980). Rather than measuring population density per square kilometre of land, we measured population density per acre of crop land, which gives a better measure of pressure on land. As outlined above, areas of heaviest pressure on land were in the

\section{Table I List of 12 variables used in the model}

Population density on cropped land

$\%$ of crop land under potatoes 1851

$\%$ population living in towns 1841

$\%$ of cultivated land under grain 1851

Average holding size

Distance to the coast

Accessibility to urban areas

Proximity to workhouses

Mean elevation

Persons per building 1841*

Male-female ratio $1841^{*}$

$\%$ uninhabited dwellings $1841 *$

*Indicates variable that did not go into the model. 
west of the country, where crop land was scarcer than in the east.

2 Percent of crop land under potatoes: This variable was included as over-dependence on the potato has been the most enduring explanation for the famine within famine historiography (Bourke 1993). Mapping potato acreage as a percentage of crop production allows us to identify those areas where potato cultivation was most prominent and to examine the relationship between potato cultivation and population decline.

3 Percent population living in urban settlements: This variable was included in an attempt to examine the extent to which the famine was primarily a rural phenomenon. Much of the literature stresses rural depopulation as one of the primary outcomes of the event (O'Rourke 1991; Whelan 1999) and an examination of the data mapped at ED level suggests that areas of less population decline and population increase were areas that contained urban settlements. However, there were many towns and villages that did suffer losses. Percent population living in urban settlements was included to measure the relationship between clustered/urban settlement and population decline.

4 Percent of land under grain: This was included to examine the extent to which grain production and commercial farming was related to population decline. Grain was largely a commercial crop in mid-nineteenth-century Ireland and much has been written on the extent to which grain was exported from Ireland during the famine (Bourke 1976; Kinealy 1997; Woodham-Smith 1962). It is now well recognised that while grain continued to be exported during the famine, much Irish grain was retained for sale (often at high prices) locally (Donnelly 1989; O'Grada 1993).

5 Average holding size: This was included to examine the relationship between larger holdings and population decline. One of the more significant impacts of the famine was the reduction in the number of small farms and the increase in larger farms (Turner 1996). This was an effect of the expansion of farms in the wake of land clearances before the famine and the continual disappearance of small farms that occurred during the famine as families died, gave up their holdings to receive relief or emigrated. Average holding size was included to examine the extent to which areas that experienced large population decline had larger holdings in 1851 (places that had undergone clearances either during or before the famine and places characterised by more land-intensive and less labour-intensive pastoral farming).
6 Distance to the coast: This variable was included to examine the extent to which coastal areas may have fared better than inland areas due to the likely availability of alternative food supplies in coastal areas. Jones-Hughes's (1965) work on the famine in east Leinster found that parishes with coastal frontages suffered less population decline than those inland. Others have argued than the consumption of rancid shellfish often exacerbated the death rate of many who sought relief from the coast. Here we included this variable to examine the way in which the effects of coastal living may have varied from place to place.

7 Accessibility to towns: This variable was included to examine the extent to which rural-to-urban migration exacerbated population decline in areas outside towns. A report from the town of Carrick-on-Shannon from 1847, for example, argued that this town did 'especially suffer as the destitute who come in from remote districts ... are unable to return, and crawl through the town begging or die by the wayside'. 6

8 Workhouse accessibility: This variable examines the extent to which the location of a workhouse may have contributed to depopulation in neighbouring EDs. Contemporary accounts as well as visual imagery produced during the period provide a vivid picture of people crowding into towns and clamouring at workhouse doors in search of relief or admittance (Killen 1996; O'Connor 1995).

9 Mean elevation: Elevation is a measure of economic marginality. Families who had been cleared from estates either before or during the famine often resorted to living in marginal areas on the edges of bogs and roads, as well as in upland regions. Here land was less favourable for food production and people depended heavily on the easily grown and high calorific potato. Upland lazybeds, in which potatoes were grown, are still evident in the Irish landscape today. Some of the literature has identified that people living in more upland regions suffered more population decline than those living in lower-lying areas (JonesHughes 1965; Smyth 1983). We included mean elevation in the model to examine the extent to which upland marginal areas were places of high population decline.

10 Persons per building: This variable is a measure of over-crowding. This may have been a symptom of pre-famine evictions or the abandonment of holdings that occurred during the famine as those who lost or gave up their homes moved in with neighbours or relatives. Moreover, while people died of starvation during the famine, the literature suggests that the majority of deaths were 
caused by infectious disease exacerbated by the weakened conditions of the people living in overcrowded conditions (Mokyr and O'Grada 2002; O'Grada 2006). This variable was included, therefore, to examine the extent to which household over-crowding (a symptom of poverty) might have impacted on population decline.

11 Male-female ratio: This is an indicator of peripheral areas and is used to examine the extent to which peripherality might have been related to population decline. Parts of the west of Ireland, for example, which suffered heavy population losses during the famine, have been identified as areas of male surplus in 1841, while in the east of the country, where population losses were lower, female surpluses were more prevalent (Kennedy et al. 1999).

12 Finally, the proportion of uninhabited houses was included to examine the extent to which areas that had been characterised by desertion before the famine (pre-famine emigration) were also areas that experienced population decline during the famine. Over 1 million people emigrated from Ireland in the first half of the nineteenth century and the impact of this movement was uneven across the island (Fitzpatrick 1989). Research on Irish emigration patterns has shown that emigrants often followed in the footsteps of relatives or neighbours who had already emigrated. This variable therefore reflects the extent to which the pre-famine exodus might have contributed to population decline during the famine.

\section{Model building}

Having selected 12 potential explanatory variables from the literature to examine the differential effects of the famine on ED populations, these variables were then subjected to a statistical model-building procedure in order to establish if any further reduction in the set were possible, so as to arrive at a reduced set of highly salient explanatory variables of population change. This was done as follows.

Step 1: Each of the 12 variables in turn was included in a simple model in which the dependent variable was percentage population change 1841-51 and the sole independent variable was one of the 12 variables listed in Table I. This model was then calibrated by GWR and the Akaike Information Criterion (AIC), a goodness-of-fit statistic, was computed (see Fotheringham et al. 2002). The variable producing the best goodness-of-fit to the data was retained in the model.

Step 2: Using the model established in Step 1, each of the remaining 11 variables not selected for the model was entered into the model in turn, so that 11 new models, each containing two independent variables, were obtained. These models were then calibrated by GWR and the best model based on goodness-of-fit retained.

Step 3: Using the model established in Step 2, each of the remaining 10 variables was added in turn to this model and the model calibrated by GWR. The model producing the best goodness-of-fit was retained.

This process continued until the addition of an extra variable failed to improve the goodness-of-fit of the model, indicating that the variables not selected in the model played no significant role in determining spatial variations in population decline. Three variables, those listed with an asterisk in Table I, were deemed to be not relevant and played no further role in the analysis. ${ }^{7}$ The order of importance of the variables in the model and the AIC value at each step are displayed in Figure 5. As can be seen, the three

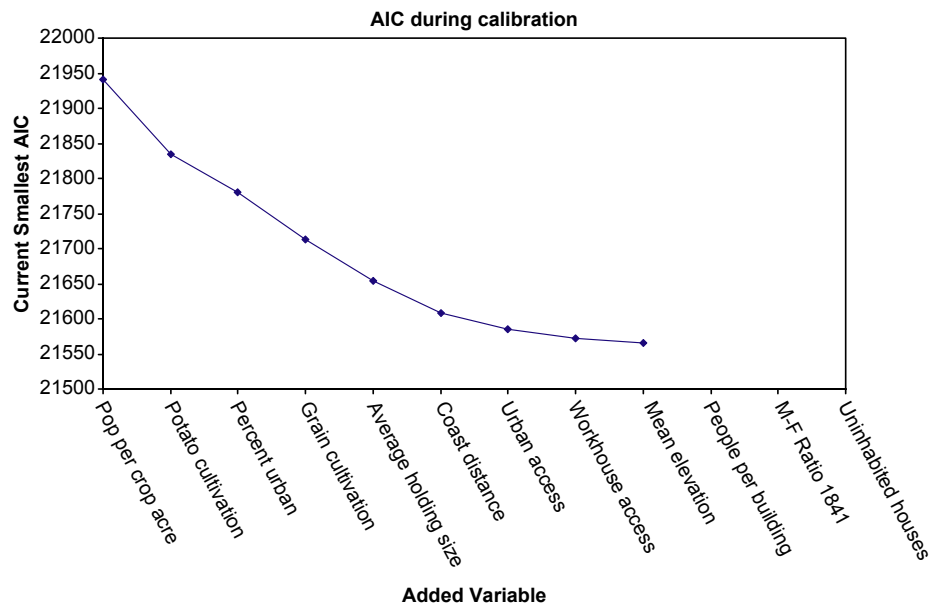

Figure 5 Variables and AIC value for each 
most important variables influencing population decline are: population density on cropped land, the percentage of potatoes grown on cropped land in 1851, and the percentage of the population living in urban areas within each ED. The nature of these relationships, and others, is now examined more closely.

\section{Measuring relationships: global regression analysis}

Using the nine explanatory variables deemed to be most relevant in understanding the spatial variation in population decline, a global regression model was calibrated in order to quantify the relationships, at a national level, between population change and each of the variables. The results of this calibration are shown in Table II, which lists each variable and its associated $\mathrm{t}$ value, indicating both the strength and direction of the various relationships. It is important to note that the relationships described here are 'global' in the sense that they represent average relationships over the whole country and therefore the order of importance of the explanatory variables in terms of being related to population change is different from GWR, where local variations in relationships are emphasised. The results in Table II suggest that the effects of the famine were more severe in EDs suffering population pressure (those with high population density on cropped land), having a high percentage of cropped land under grain in 1851, where average holding size in 1851 was high, that were in close proximity to EDs in which a workhouse was located, that were near to towns (facilitating rural- to-urban migration), and away from the coast. Conversely, EDs suffered less population decline in more upland areas, when more of the population lived in clustered settlements ${ }^{8}$ and where a relatively high percentage of the cropped land was under potatoes in 1851.

Most of these global findings are reasonably intuitive and support many of the hypotheses in the literature. The effects of the famine on population decline were felt most in areas experiencing high rural population pressure away from the coast and in close proximity to both workhouses and towns, both of which induced people to leave. Perhaps surprisingly, EDs in upland areas suffered less than EDs in lowland areas. Greater population decline being found in areas having larger farm holdings and more cultivated land under grain probably reflects the situation where abandoned holdings were amalgamated and where commercial grain and cattle production came to dominate those areas that had undergone clearances before the famine or experienced severe population loss during the famine. The global result that population decline was higher in areas with lower percentages of potatoes seems counterintuitive. However, considering that the 1851 data may represent postfamine recovery, it may be that areas in which potato cultivation was relatively strong in 1851 were areas that had suffered less during the famine. Consequently, the negative psychological association between potatoes and death left after the famine may not have been as strong in these areas. An alternative

Table II Variables used in global regression model and associated t values

\begin{tabular}{|c|c|c|c|c|c|c|c|c|}
\hline Effect & Min & $\operatorname{Max}$ & Sum & Mean & Median & $S D$ & $t$ value & $\begin{array}{l}\text { Population decline } \\
\text { was more severe when }\end{array}$ \\
\hline $\begin{array}{l}\text { Population density } \\
\text { on cropped land }\end{array}$ & 0.3983 & 13.1954 & 5678.9169 & 1.833683 & 1.5935 & 1.045041 & -27.79 & $\begin{array}{l}\text { Higher population } \\
\text { density on cropped } \\
\text { land }\end{array}$ \\
\hline Grain cultivation & 9.1493 & 80.5464 & 156412.3267 & 50.504465 & 51.1429 & 11.195945 & -15.64 & $\begin{array}{l}\text { Greater proportion } \\
\text { of cultivated land } \\
\text { under grain }\end{array}$ \\
\hline $\begin{array}{l}\text { Average holding } \\
\text { size }\end{array}$ & 4.6712 & 296.6585 & 120782.4078 & 38.999809 & 32.6612 & 25.71306 & -15.16 & $\begin{array}{l}\text { Areas with larger } \\
\text { holding sizes }\end{array}$ \\
\hline $\begin{array}{l}\text { Percent } \\
\text { population urban }\end{array}$ & 0 & 49.9674 & 11800.0232 & 3.810146 & 0 & 9.398629 & 9.11 & $\begin{array}{l}\text { Lower } \% \text { of } \\
\text { population living in } \\
\text { urban areas }\end{array}$ \\
\hline $\begin{array}{l}\text { Workhouse } \\
\text { accessibility }\end{array}$ & 0 & 0.4821 & 164.1324 & 0.052997 & 0.046 & 0.030891 & -8.08 & Nearer to workhouse \\
\hline $\begin{array}{l}\text { Urban } \\
\text { accessibility }\end{array}$ & 407.2674 & 9203.7623 & 6624854.2888 & 2139.119887 & 2138.2998 & 658.600285 & -5.91 & Nearer to town \\
\hline Potato cultivation & 2.2118 & 81.5029 & 49318.042 & 15.924457 & 14.5463 & 7.600588 & 3.62 & $\begin{array}{l}\text { Less cultivated land } \\
\text { under potatoes }\end{array}$ \\
\hline $\begin{array}{l}\text { Distance to the } \\
\text { coast }\end{array}$ & 10.6301 & 85899.0282 & 80618118.9754 & 26031.036156 & 21063.9745 & 21658.402556 & -3.44 & $\begin{array}{l}\text { Farther away from } \\
\text { the coast }\end{array}$ \\
\hline Mean elevation & 0 & 448.022 & 414151.7637 & 133.726756 & 132.451 & 73.073211 & 2.47 & $\begin{array}{l}\text { On less upland } \\
\text { regions }\end{array}$ \\
\hline
\end{tabular}

R square $=0.26$. 
Table III An example of GWR output for a sample of EDs

\begin{tabular}{|c|c|c|c|c|c|c|c|c|}
\hline \multirow[b]{2}{*}{ Name } & \multicolumn{2}{|c|}{ Grain cultivation } & \multicolumn{2}{|c|}{ Mean elevation } & \multicolumn{2}{|c|}{$\begin{array}{l}\text { Population density on } \\
\text { cropped land }\end{array}$} & \multicolumn{2}{|c|}{ Potato cultivation } \\
\hline & $\begin{array}{l}\text { parameter } \\
\text { estimate }\end{array}$ & $\mathrm{t}$ value & $\begin{array}{l}\text { parameter } \\
\text { estimate }\end{array}$ & $\mathrm{t}$ value & $\begin{array}{l}\text { parameter } \\
\text { estimate }\end{array}$ & $\mathrm{t}$ value & $\begin{array}{l}\text { parameter } \\
\text { estimate }\end{array}$ & $\mathrm{t}$ value \\
\hline Carnagarve & -0.255 & -1.791 & 0.000 & -0.003 & -22.347 & -5.118 & 1.103 & 0.265 \\
\hline Crossbane & -0.298 & -2.054 & 0.002 & 0.048 & -22.455 & -5.509 & -0.574 & -0.141 \\
\hline Enniskeen & -0.244 & -1.614 & -0.008 & -0.209 & -20.587 & -4.118 & 3.145 & 0.680 \\
\hline Killinkere & -0.179 & -1.336 & 0.009 & 0.289 & -22.134 & -4.992 & -0.541 & -0.122 \\
\hline Kingscourt & -0.281 & -1.770 & 0.020 & 0.541 & -17.504 & -3.484 & 3.215 & 0.687 \\
\hline Lisagoan & -0.210 & -1.407 & 0.007 & 0.186 & -19.206 & -3.730 & 3.598 & 0.734 \\
\hline Mullagh & -0.327 & -2.290 & -0.007 & -0.175 & -21.817 & -5.528 & 0.101 & 0.026 \\
\hline Shercock & -0.078 & -0.555 & 0.003 & 0.094 & -20.586 & -4.019 & 3.712 & 0.716 \\
\hline Skeagh & -0.078 & -0.589 & -0.003 & -0.099 & -21.259 & -4.212 & 4.059 & 0.796 \\
\hline Taghart & -0.133 & -0.932 & 0.002 & 0.058 & -20.233 & -3.948 & 3.860 & 0.752 \\
\hline \multirow[t]{3}{*}{ Termon } & -0.150 & -1.180 & 0.018 & 0.558 & -21.029 & -4.745 & -1.698 & -0.375 \\
\hline & \multicolumn{2}{|c|}{ Workhouse accessibility } & \multicolumn{2}{|c|}{ Average holding size } & \multicolumn{2}{|c|}{ Distance to the coast } & \multicolumn{2}{|c|}{ Urban accessibility } \\
\hline & $\begin{array}{l}\text { parameter } \\
\text { estimate }\end{array}$ & $\mathrm{t}$ value & $\begin{array}{l}\text { parameter } \\
\text { estimate }\end{array}$ & $\mathrm{t}$ value & $\begin{array}{l}\text { parameter } \\
\text { estimate }\end{array}$ & $\mathrm{t}$ value & $\begin{array}{l}\text { parameter } \\
\text { estimate }\end{array}$ & $\mathrm{t}$ value \\
\hline Carnagarve & -1.627 & -0.431 & -7.425 & -2.431 & 6.323 & 2.342 & -25.493 & -2.555 \\
\hline Crossbane & -3.266 & -0.813 & -7.309 & -2.386 & 7.051 & 2.445 & -18.923 & -1.943 \\
\hline Enniskeen & 1.648 & 0.570 & -7.597 & -2.612 & 3.778 & 1.431 & -30.589 & -2.594 \\
\hline Killinkere & -2.664 & -0.631 & -8.278 & -2.238 & 7.694 & 2.648 & -26.867 & -2.112 \\
\hline Kingscourt & 2.580 & 0.970 & -6.518 & -2.244 & -1.547 & -0.714 & -21.889 & -1.805 \\
\hline Lisagoan & 1.019 & 0.363 & -7.854 & -2.655 & 0.256 & 0.102 & -28.169 & -2.202 \\
\hline Mullagh & -0.594 & -0.173 & -6.818 & -2.492 & 6.069 & 2.221 & -18.895 & -2.183 \\
\hline Shercock & -3.837 & -1.039 & -11.368 & -3.312 & 0.657 & 0.270 & -31.648 & -2.144 \\
\hline Skeagh & -1.940 & -0.452 & -9.279 & -2.560 & 5.518 & 2.004 & -34.375 & -2.268 \\
\hline Taghart & -1.133 & -0.362 & -9.275 & -2.958 & 0.834 & 0.327 & -31.455 & -2.337 \\
\hline Termon & -1.784 & -0.438 & -9.195 & -2.304 & 9.439 & 3.005 & -24.915 & -1.823 \\
\hline
\end{tabular}

explanation might be that population decline itself led to reduced potato acreages as there were fewer people to cultivate the crop and fewer people to feed in 1851. The fact that the model only explains approximately 30 per cent of the variation in population decline across the EDs also suggests these relationships may be more complex than is assumed in a simple global model. Hence, we now explore these relationships in more detail, allowing spatial contextual effects to play a greater role.

\section{Geographically weighted regression: measuring spatial variations in the determinants of population change}

Global regression model calibration is a standard statistical procedure for quantifying relationships, other things being equal, between variables. However, it has come under strong criticism in recent years when employed on spatial data because it assumes that the relationships being measured, and by inference the processes generating these relationships, are the same everywhere. It is quite possible that social processes might be context-specific and hence vary over space. GWR is a technique that has been developed as an alternative to global regression that allows relationships to vary over space (Fotheringham et al. 1996 2002).

A standard linear model calibrated by global regression has the general form

$$
\mathrm{y}_{\mathrm{i}}=\beta_{0}+\beta_{1} \mathrm{X}_{\mathrm{i} 1}+\beta_{2} \mathrm{X}_{\mathrm{i} 2}+\ldots \beta_{\mathrm{n}} \mathrm{X}_{\mathrm{in}}
$$

where $y_{i}$ is the dependent variable, percentage population change in this case, measured at location $\mathrm{i}, \mathrm{X}_{\mathrm{i}}$ represents the explanatory variables measured at the same location and $\beta$ represents parameters that describe how a change in $X$ affects $y$. Here the parameters are assumed constant over space. If they are not constant and the processes generating the relationships being measured vary over space, then the global model parameters simply become averages of the spatially varying relationships and in fact disguise any interesting context-dependent relationships that might exist. In order to measure spatially varying relationships, a GWR version of equation (1) can be developed and takes the form: 


$$
\mathrm{y}_{i}=\beta_{0}(\mathrm{i})+\beta_{1}(\mathrm{i}) \mathrm{X}_{\mathrm{i} 1}+\beta_{2}(\mathrm{i}) \mathrm{X}_{\mathrm{i} 2}+\ldots \beta_{\mathrm{n}}(\mathrm{i}) \mathrm{X}_{\mathrm{in}}
$$

where the parameters now have an index i indicating that their value depends on the location of the local regression. This is achieved by weighting the data according to the regression location $i$ such that data near to $i$ are accorded more weight in the analysis than data recorded at locations further away. As the regression point changes, so do all the weights and hence the resulting parameter estimates in the calibration of the model become specific to a particular location i. Hence GWR calibration results not in one single global estimate of each parameter in the model but a surface of local parameter estimates that can be mapped to investigate any possible significant spatial variations in the processes being investigated. Further details on the mechanics of GWR are beyond this paper and are provided elsewhere (e.g. Fotheringham et al. 2002).

In this case, GWR was used to calibrate a model relating percentage population decline between 1841 and 1851 in each of the 3098 EDs to the nine explanatory variables listed in Table II. ${ }^{9}$ This resulted in a much improved model fit (the r-squared value increasing from 0.3 to 0.7 ) and a set of geocoded local parameter estimates for each relationship (Table III). The spatial variation of each of these sets of local parameter estimates was statistically significant in every case except those for the percentage of urban population variable, which exhibited a global relationship with population decline. For the remaining eight variables, the local parameter estimates associated with each can be mapped to show the spatial variations in the determinants of population decline. We represent the nature of these variations by mapping only the values of each local parameter estimate where they are locally statistically significant. This is done by calculating a local $t$ value for each parameter estimate (obtained by dividing each local estimate by its local standard error) and then selecting the appropriate cut-off value for the $t$ distribution. ${ }^{10}$ This leads to interesting new insights into the determinants of population change during the famine decade, as we now describe.

\section{Geographically weighted regression results}

Results derived from the model calibrated using GWR are presented in Figure 6. This shows four of the eight maps of local parameter estimates. In each map only the local parameter estimates that are significantly different from zero (here indicated by a $t$ value in excess of 3.28) are displayed.

Figure 6a describes the local parameter estimates for the relationship between population decline and population density on cropped land, accounting for variations in the other eight explanatory variables. The global parameter estimate for this relationship (Table II) is -14.9 , indicating that on average across the country if population density on cropped land rose from 5 to 6 persons per acre within an ED, the population decline over the decade for that ED would have increased by around 3 per cent. However, the GWR results indicate the nature of the variability of this relationship - something completely hidden in the single global result. The local parameter estimates are insignificant across most of Ulster, whereas they are highly significant in counties such as Roscommon, Leitrim and Sligo in Connaught and in Longford, Meath and Westmeath in Leinster. The relationship is also highly significant in Kerry and West Cork in the southeast. In these parts of the country, a similar increase in population density on cropped land from 5 persons per acre to 6 would have resulted in a population decline of over 6 per cent. Interspersed between these regions are pockets where the relationship is not significant and where population pressure appeared not to be a factor in population decline. One of these areas is the Wicklow Mountains, where population density was low before the famine. What this tells us is, firstly, that population density per acre of cropped land (a measure of population pressure in areas of food resource scarcity) was the most important factor that determined population decline at the national scale and, secondly, that this relationship was not even across the country but varied in significance from place to place. This raises important new questions about the geography of the famine in Ireland. Why, for example, was population density on cropped land so significant in areas such as Co. Roscommon? The answer may be related to grazing and clearances. The reservation of land for grazing resulted in the removal of tenants from the more fertile cattlefattening lands, which reduced the amount of land available for crop production and the need for local labour at sowing and harvest time. Peasant populations consequently were displaced to the more marginal areas, where they lived in conditions of extreme vulnerability. The other parts of the country highlighted in Figure 6a may have been characterised by similar processes. However, more detailed local history is needed into these areas to explain why the areas of high population density per acre of cropped land were those that suffered most.

Figure $6 \mathrm{~b}$ indicates the parts of the country where the density of potato cultivation in 1851 was related to population decline. The global estimate is significantly positive (1.7) indicating that if the percentage of cropped land under potatoes rose from 20 per cent to 30 per cent in 1851 , this would be associated with a reduction in population decline of under 1 per cent. 
(a)

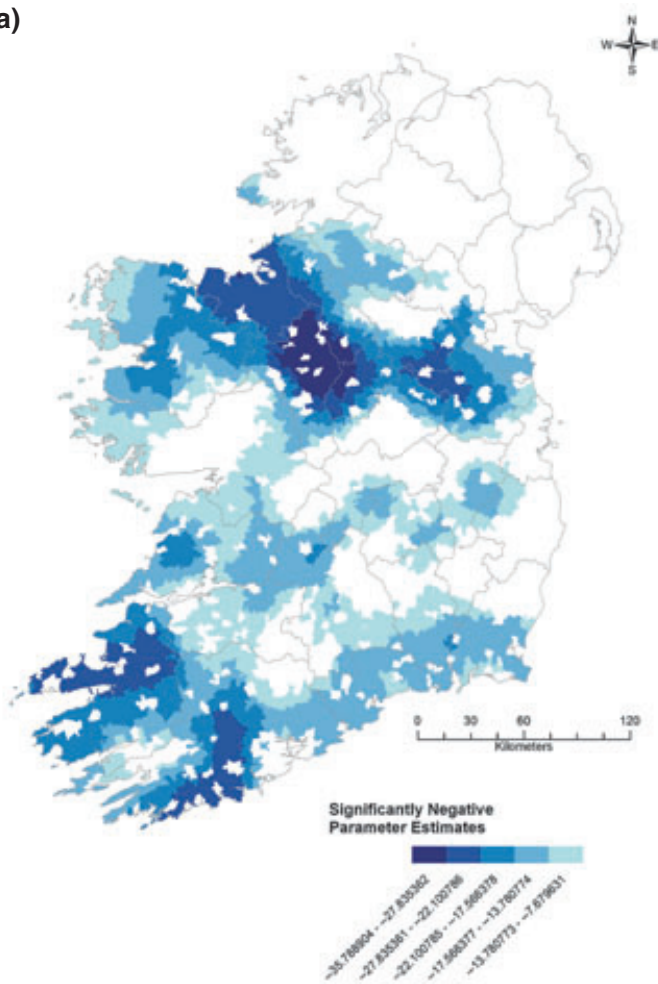

(c)
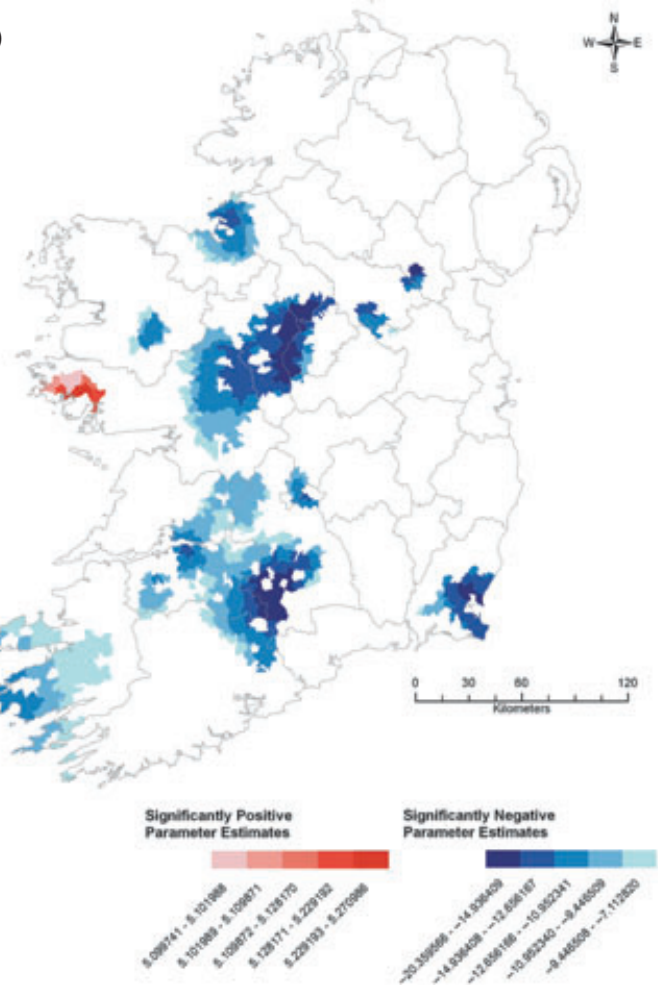

(b)
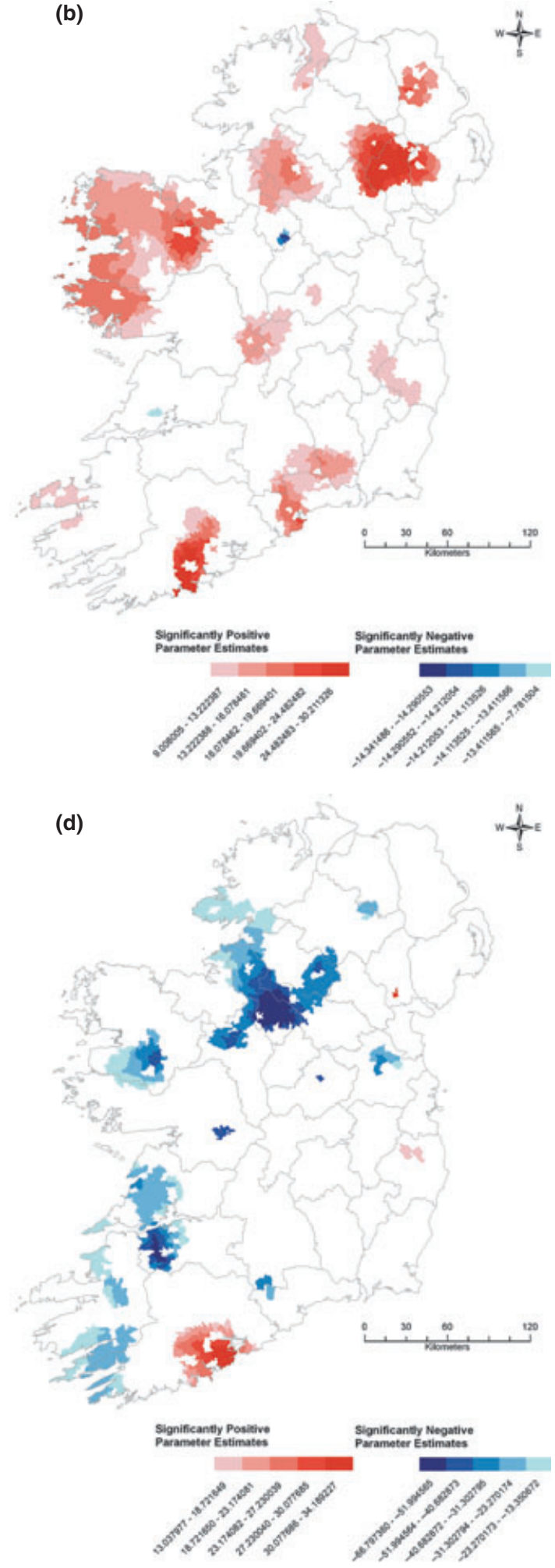

Figure 6 GWR local parameter estimates (a) population density per cropped acre; (b) potato cultivation; (c) average holding size and (d) accessibility to towns 
The vast majority of the local estimates that are significant are also positive (although most local estimates are insignificant) - in the extreme cases such as in Armagh, Mayo and south central Co. Cork, a similar increase in potato cultivation would have resulted in a 12 per cent reduction in population decline. The results may seem surprising - the expectation would be that areas of high potato dependency would be areas of greater population decline. The result, however, could be explained by the fact that this agricultural variable represents post-famine conditions. The parts of Mayo and west Galway and in Armagh, Fermanagh and south central Cork, where potatoes were no longer grown in 1851, were areas that suffered relatively large population declines during the 1840s. Conversely, areas where potatoes were still grown in 1851 were less likely to have suffered large population losses during the famine. In only a very small part of the country, southeast Leitrim, is a significant negative relationship found between 1851 potato cultivation and population decline. Here places with a higher proportion of crop land under potatoes were areas that suffered higher losses. What this tells us then is, firstly, that there is a slight negative correlation between potato cultivation in 1851 and population decline, other things being equal, at the national level and, secondly, that this relationship varies across space with no significant relationship over much of the country. This raises important questions regarding post-famine potato cultivation. Population decline may have resulted in reduced cultivation due to an overall reduction in the demand for food, or it could be that in areas where the famine hit hardest people were less likely to return to potato cultivation, having suffered the impacts of prolonged blight. In other areas (southeast Leitrim), it would seem that potato cultivation suffered very little from the famine. Again more detailed local analysis of the particular regions highlighted in Figure $6 \mathrm{~b}$ is needed to examine these possibilities in more detail. This analysis, however, not only enables us to raise these questions but also allows us to pinpoint those areas in which the answers to these questions might be found.

Figure $6 \mathrm{c}$ depicts the local parameter estimates for the variable average holding size in 1851 relating post-famine land ownership patterns to population decline during the famine decade. The global relationship is significantly negative indicating that land reorganisation had taken place by 1851, such that EDs having relatively large agricultural holdings in 1851 were those that experienced the worst of the famine in terms of population loss. Large-scale rural depopulation facilitated land reorganisation with the amalgamation of smaller plots and the replacement of people with animals or commercial crops (Whelan
1995). Interestingly, the local parameter estimates suggest that such a relationship was not an islandwide phenomenon. Over much of the country, including almost all of Ulster and most of Leinster, there is no significant relationship. The areas of the country in which a negative relationship between holding size and population loss was found are in five main clusters: Sligo; Roscommon, south Leitrim, Longford and east Galway; Wexford; Tipperary and Limerick; and Kerry. Interestingly, there is one area in west Galway where the relationship is significantly positive. Here larger holdings in 1851 are associated with less population decline, suggesting that farm consolidation neither exacerbated nor benefited from rural depopulation here as it did elsewhere. Again, examination of the range of farm sizes and type of agriculture practised here is needed to explain why this area differs from the national trend.

Figure 6d depicts the local relationships between population decline and proximity to towns. Globally, the relationship is significantly negative $(-4.9)$, indicating that as proximity to towns increased, population decline increased, presumably due to increased ruralto-urban migration. However, the GWR results in Figure $6 \mathrm{~d}$ belie the nature of this conclusion because in most of the country there is no significant evidence of raised levels of rural-to-urban migration closer to towns. It is only around towns in four areas, Leitrim and northwest Cavan; southwest Mayo; Limerick and southwest Clare; and Kerry, that we see strong evidence of raised levels of rural-to-urban migration closer to towns. Conversely, around the city of Cork we find significant positive relationships between population decline and proximity to the urban area, suggesting that the beneficial effects of living in Cork during the famine diffused out into the surrounding EDs.

Finally, we can examine the performance of the model in different parts of the country to assess how well the nine explanatory variables used together in the model replicate the local variations in population change. The global $r$-squared value was 0.3 , meaning that only 30 per cent of the spatial variation in population change was 'accounted for' by the global model and 70 per cent remained unaccounted for. The poor fit is probably in part because the relationships we are measuring vary spatially and are not global. We can assess how well the local model replicates the variations in population change in two ways: by reporting the overall r-squared value from the GWR calibration, which was 0.7 , and also by mapping the local r-squared values from the GWR calibration. These are displayed in Figure 7, which presents a new geography to be explained. The model replicates variations in population decline well in some areas - the large band stretching east to west from Leinster to Connaght, down the east coast and through much of the 


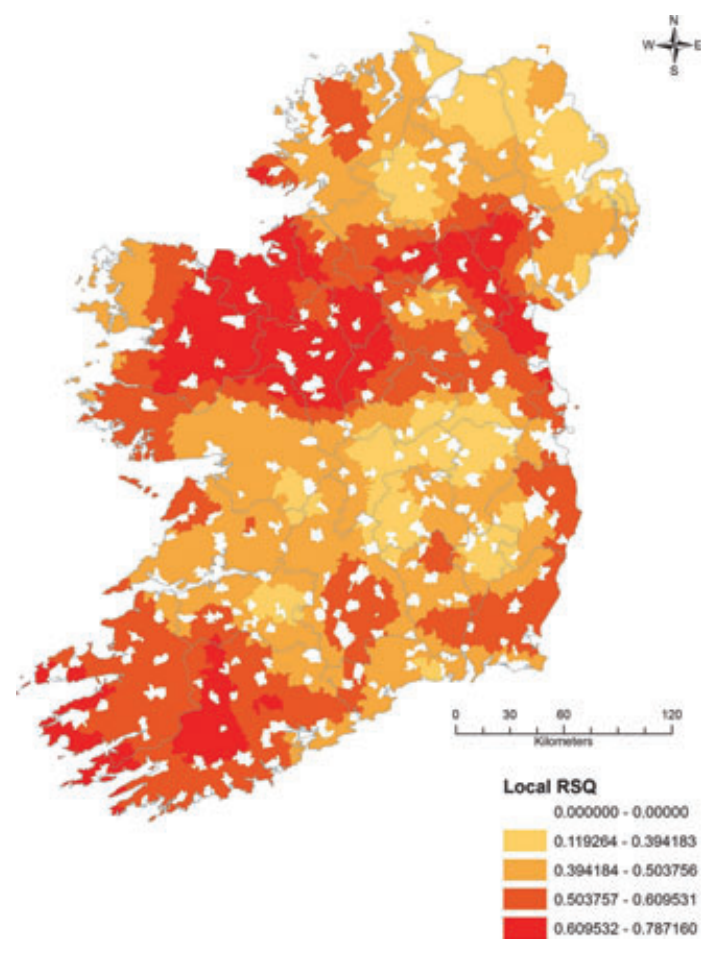

Figure 7 Local r-squared values

southwest. The local model performs least well in Ulster, where the determinants of and the effects of the famine appear to be quite different from the rest of Ireland. Overall Ulster fared better than the rest of the country where population decline was lower than the national average. Here, land tenure systems were different and a fledgling industrial sector was developing. The model also performs poorly across much of the midlands where again perhaps agricultural patterns and population pressures were different.

\section{Conclusions}

Despite the extensive literature on the Irish famine there has been little consensus on the factors that contributed to the disaster. This is because the Irish famine, as with events in history more generally, is often thought of as a singular event. As geographers we know that the Irish famine was not a singular event but, being experienced differently in different areas, was a series of multiple, albeit related, events. In this research we have considered the Irish famine as 3098 individual events and used data from those events in the analysis of processes at the national scale. In doing so we have, for the first time, mapped population change at the scale of ED, thereby revealing patterns of population change for this period of Irish history not previously visualised and also collected and mapped a range of ED characteristics to help us explain why some areas suffered more population decline than others. Having a database of ED characteristics allows us then not only to visualise spatial patterns but also to statistically measure the relationship between possible explanatory variables, identified and debated in the extensive famine literature, and population decline. While the set of variables included here does not encompass all the possible local variables that may have exacerbated or alleviated population change, here we have measured the relationship between population decline and nine explanatory variables. In doing so, we have provided an indication of the nature of the relationship between each variable and population decline and a measure of the strength of that relationship at the national scale. This allows us to evaluate the extent to which these particular variables were more likely or less likely to characterise places that suffered high population losses. The type of statistical analysis used here enables us to engage with existing famine literature by providing a measured assessment of the relationship between factors identified in that literature and depopulation at this time in Irish history.

Moreover, while we know that standard regression can provide us with a measure of the relationship between variables and population decline for the island as a whole, we also know that such analysis can obscure important spatial variations in these relationships. To remove this problem, we have used GWR, a form of regression analysis that produces local rather than global parameter estimates. In this instance, GWR allows us to investigate detailed spatial variations in the determinants of population loss during the famine decade across Ireland that highlights the paucity of information provided by the classic global modelling approach. For example, the global analysis suggests there is a strong negative relationship between population loss and population pressure. However, the GWR results show this was not the case for the island as a whole. In Ulster, for example, population pressure on land was not found to be significantly related to population loss. Other processes were driving population decline here. Thus while population pressure on land has long been put forward as an explanation for the severity of population decline (Connell 1975; Freeman 1957; Grigg 1980), we show here that while it was an important factor in some areas, it did not drive population decline everywhere. Examination of the GWR local parameter estimates for the other variables used in the model shows that the relationship between each variable and population decline has its own geography. The significance of this is that GWR allows us to arrive at a more spatially sensitive consideration of the relationships between possible explanatory variables and population decline by enabling us to identify where particular variables 
are important, or not, as well as their level of importance. This allows us to think about the reasons why particular variables are more important in some areas than in others. More detailed local analysis is needed to explain these reasons, but highlighting the particular areas where variables are important helps to pinpoint those areas in which the answers to these questions might be found. This research therefore bridges the gap between the detailed qualitative local research that has been carried out on the impacts of the Irish famine at a range of scales and the national statistical data that are available for this period in Irish history by using local data to measure the processes that underpin a national disaster and by facilitating the interrogation of national narratives with local evidence.

From a broader theoretical perspective, this research demonstrates how quantitative spatial analysis can bridge the gap between local and global contexts and in doing so can contribute to historiographical debates. The causes of the Irish famine have received much attention in Irish historiography and have often been put forward in highly politicised terms (O'Grada 2006). As outlined earlier, the geographically uneven nature of the literature on the topic, itself carried out at varied spatial scales and using varied methodologies, also makes consensus difficult. Informed by this literature and driven by a desire to make sense of the famine as a complex phenomenon with a complex geography, we have used the statistical data to interrogate the issues raised in that literature. Population density on cropped land (Connell 1975; Freeman 1957; Grigg 1980), percentage of land under potato cultivation (Bourke 1993), average holding size (Turner 1996), and proximity to urban areas (Cousens 1960) have all been put forward as factors that contributed to depopulation during the Irish famine. Some of these variables are themselves the outcome of wider and earlier policies towards the management of the Irish people and the Irish landscape. Here we have used statistical and spatial analysis to interrogate the geography of these explanations. In doing so, we have demonstrated that the relationships between these variables and population decline are not island-wide phenomena but vary from one part of the island to another and identified the areas in which each variable was significant. Revealing the geography of the catastrophe, the geography of possible determinants, and a geography of relationships, this research facilitates a much more nuanced view of the way in which this event impacted on the Irish landscape in the mid-nineteenth century and demonstrates the importance of geographical perspectives in historical research.

Finally, the lack of quantitative data available for the pre-famine period has led to it being regarded as a 'statistical dark age' (O'Grada 1989, 122) and the consequent fissure that exists between the level and certainty of our knowledge of pre- and post-famine Ireland has led to the period being regarded as somewhat of a historiographical hinge. GIS, as a tool for measuring, managing and mapping large datasets, has enabled us to use the existing data to bridge that fissure and demonstrates that, while we cannot create new sources for this period in Irish history, we can engage with existing data in new ways.

\section{Acknowledgements}

The research for this article has been funded by an IRCHSS Senior Research Scholarship (2009-2010) and by the National Centre for Geocomputation. All maps have been produced using the NCG Mapping Licence: Ordnance Survey Ireland Licence Number EN.0072711 @ O Ordnance Survey Ireland/Government of Ireland. We would like to thank Professor Chris Brunsdon for his help with the data used in this paper. Finally, we would like to thank the journal editors and the anonymous referees for their comments on earlier drafts of the paper.

\section{Notes}

1 These data are now downloadable from the Atlas of Irish Famine Data, available at http://ncg.nuim.ie/historical-atlas (Accessed 11 March 2011).

2 These dramatic reductions in population are not due to a small number of issues. The lowest population count of any ED in 1841 was 165 and the lowest population of any ED to suffer a greater than 50 per cent loss of population was 544 .

3 Out-migration to a neighbouring ED or to another part of Ireland.

4 The 1851 census records over 200000 people living in workhouses.

5 Variables that were highly skewed were transformed into natural logarithms prior to subsequent regression analyses.

6 Papers relating to proceedings for relief of distress, and state of unions and workhouses in Ireland, Series Five, 1847-48 [919] 137.

7 Both the number of persons/building and the percentage of uninhabited buildings reflect attempts to measure population pressure, but in the model selection process, population density per cropped land appears to be a superior measure of population pressure and is included within the model. The male/female population ratio was found to be unimportant in explaining variations in population decline.

8 Clustered settlements, identified with ' $\mathrm{T}$ ' in the 1851 census, are settlements containing more than 20 houses. Here we only included settlements that contained more than 200 people.

9 The R-squared statistic for the model increased to 0.71 from 0.26 for the global model and the optimal number 
of nearest neighbours obtained in the GWR calibration of the bandwidth was 143 out of the 3098 EDs, indicating the presence of very localised relationships in the effects of the famine on population change.

10 The cut-off value for declaring a local parameter estimate to be significantly different from zero (and hence indicating that there is a probability of less than 0.05 that the relationship is simply an artefact of the data) is 3.28. This value is derived by using a correction factor for multiple hypothesis testing and is much more stringent than the usual value around 2.0.

\section{References}

Bourke A 1959/60 The extent of the potato crop in Ireland at the time of the famine Statistical and Social Inquiry Society of Ireland 1-35

Bourke A 1965 The agricultural statistics of the 1841 census: a critical review Economic History Review 18 376-91

Bourke A 1976 The Irish grain trade Irish Historical Studies 20 156-69

Bourke A 1993 The visitation of God? The potato and the great Irish famine Lilliput Press, Dublin

Connell K 1975 The population of Ireland 1700-1845 Oxford University Press, Oxford

Cousens S H 1960 Regional death rates in Ireland during the great famine, from 1846 to 1851 Population Studies 14 55-74

Cowman D 1995 The famine in Waterford 1845-1850: Teacht Na Bprátaí Dubha Geography Publications, Dublin

Donnelly J S 1989 The administration of relief, 1846-7 in Vaughan W E ed $A$ new history of Ireland V: Ireland under the Union 1801-1870 Oxford University Press, Oxford 294-306

Duffy P J 2004 To and from Ireland: planned migration schemes c. 1600-2000 Geography Publications, Dublin

Ell P S and Gregory I N 2005 Demography, depopulation and devastation: exploring the geography of the Irish Potato Famine Historical Geography 33 54-75

Fitzpatrick D 1989 Emigration 1801-70 in Vaughan W E ed A new history of Ireland V: Ireland under the Union 18011870 Oxford University Press, Oxford 562-622

Fotheringham A S, Brunsdon C and Charlton M E 2002 Geographically weighted regression: the analysis of spatially varying relationships Wiley, Chichester

Fotheringham A S, Charlton M R and Brunsdon C 1996 The geography of parameter space: an investigation into spatial non-stationarity International Journal of GIS 10 605-27

Freeman T W 1957 Pre-famine Ireland: a study in historical geography Manchester University Press, Manchester

Gray P 1999 Famine land and politics: British government and Irish society 1843-1850 Irish Academic Press, Dublin

Gregory I N and Ell P S 2005 Analyzing spatiotemporal change by use of national historical geographical information systems: population change during and after the great Irish famine Historical Methods: A Journal of Quantitative and Interdisciplinary History 38 149-67

Grigg D 1980 Population growth and agrarian change: an historical perspective Cambridge University Press, Cambridge
Guinnane T W and O'Grada C 2000 The workhouses and Irish famine mortality Department of Economics UCD Centre for Economic Research Working Paper Series WP100/10

Hickey P 1995 Famine mortality and emigration: a profile of six parishes in the Poor Law Union of Skibereen in O'Flannagan P and Buttimer C eds Cork: history and society Geography Publications, Dublin 873-918

Jones-Hughes T 1965 East Leinster in the mid-19th century Irish Geography 3 227-41

Kennedy L, Ell P, Crawford M and Clarkson L 1999 Mapping the great Irish famine: a survey of the famine decades Four Courts Press, Dublin

Kenny K 2003 Diaspora and comparison: the global Irish as a case study The Journal of American History 90 134-62

Killen J 1996 The famine decade: contemporary accounts, 1841-1851 Blackstaff Press Ltd, Dublin

Kinealy C 1997 A death-dealing famine: the great hunger in Ireland Pluto Press, Dublin

Kinealy C and Parkhill T 1997 The famine in Ulster Belfast Ulster Historical Foundation, Belfast

Lloyd D 2007 The political economy of the potato Nineteenth Century Contexts 29 311-35

McDonagh O 1956 Irish emigration to the United States of America and the British colonies during the famine in Edwards R D and Williams T D eds The great famine: studies in Irish history 1845-52 The Lilliput Press, Dublin (reprinted 1994) 319-90

Mokyr D and O'Grada C 2002 What do people die of during famines? The great Irish famine in comparative perspective European Review of Economic History 6 339-64

Murphy I 1996 A people starved: life and death in west Clare Irish Academic Press, Dublin

Nally D 2011 Human encumbrance: political violence and the great Irish famine University of Notre Dame Press, Notre Dame IN

O'Brien G 1982 The establishment of poor law unions in Ireland 1838-1943 Irish Historical Studies 23 97-120

O'Connor J 1995 The workhouses of Ireland: the fate of Ireland's poor Anvil Books, Dublin

O'Grada C 1989 Poverty, population, and agriculture, 180145 in Vaughan W E ed $A$ new history of Ireland V: Ireland under the Union Clarendon Press, Oxford 108-16

O'Grada C 1993 Ireland before and after the famine: exploration in economic history 1800-1925 Manchester University Press, Manchester

O'Grada C 1994 Ireland: a new economic history Oxford University Press, Oxford

O'Grada C 1999 Black '47 and beyond: the great Irish famine in history, economy, and memoir Princeton University Press, Princeton NJ

O'Grada C 2006 Ireland's great famine: interdisciplinary perspectives University College Dublin Press, Dublin

O'Rourke K 1991 Agricultural change and rural depopulation 1845-1876 The Journal of Economic History 51 464-6

Póirtéir C 1995 The great Irish famine Cork Mercier Press, Cork

Smyth W J 1983 Landholding changes, kinship networks and class transformation in rural Ireland: a case study from County Tipperary Irish Geography 16 16-35 
Smyth W J 2007 Map-making and Ireland: presences and absences in Crawford Art Gallery ed (C)artography: mapmaking as artform Crawford Art Gallery, Cork 4-14

Turner M E 1996 After the famine: Irish agriculture 1850-1914 Cambridge University Press, Cambridge

Whelan K 1995 Pre- and post-famine landscape change in Póirtéir $\mathbf{C}$ ed The great Irish famine Mercier Press, Cork $19-33$
Whelan K 1999 Economic geography and the long-run effects of the great Irish famine The Economic and Social Review 30 1-20

Woodham-Smith C 1962 The great hunger; Ireland 1845-49 Hamish Hamilton, London

Yager T 1996 Mass eviction in the Mullet peninsula during and after the Great Famine Irish Economic and Social History 23 24-44 